Psychology of

Music

\title{
Self-determined motivation for practice in university music students
}

\begin{tabular}{|c|c|}
\hline Journal: & Psychology of Music \\
\hline Manuscript ID: & POM-15-845.R1 \\
\hline Manuscript Type: & Original Empirical Investigations \\
\hline Keyword: & $\begin{array}{l}\text { self-determination theory, Motivation, psychological needs, autonomy, } \\
\text { conservatoire, music education, Practice }\end{array}$ \\
\hline Abstract: & $\begin{array}{l}\text { This study adopted self-determination theory as means to understanding } \\
\text { the motivation of university music students. The self-determination theory } \\
\text { framework contends that three psychological needs of competence, } \\
\text { relatedness, and autonomy must be fulfilled in order to maintain wellbeing } \\
\text { and fulfilment. In turn, needs fulfilment results in autonomous motivation, } \\
\text { in which activities are perceived to be aligned with the self and experienced } \\
\text { as personally important, interesting, and enjoyable. We surveyed } 410 \\
\text { students from schools of music in nine universities in Australia and New } \\
\text { Zealand to examine whether needs fulfilment and autonomous motivation } \\
\text { within the university music learning context would explain context-specific } \\
\text { affect and behaviour. Hypothesised relationships were tested using } \\
\text { structural equation modelling and an acceptable model was obtained. } \\
\text { Psychological needs fulfilment and autonomous motivation explained more } \\
\text { frequent practice, more frequent quality practice, and a higher preference } \\
\text { for challenging tasks. This study is among the first self-determination } \\
\text { theory studies in the domain of music learning at the university level, and } \\
\text { thus the results are described in terms of the potential of this theory to } \\
\text { more fully explain interesting and under-researched aspects of this } \\
\text { environment, including student wellbeing, anxiety, preparations for a long- } \\
\text { term career in music, and pedagogical implications. }\end{array}$ \\
\hline
\end{tabular}


Learning instrumental music performance at the university level can be difficult. Students face considerable challenges, including developing a relationship with a studio teacher, learning to cope with competitive social environments, and planning for an uncertain and testing career (Bennett \& Stanberg, 2008; Gaunt, 2011).

Among these difficulties is sustaining the many hours of practice required to develop performance ability. Practice is a skill that students must hone without much substantial guidance, because in studio lessons, technique and repertoire tend to be prioritised, and little instructional time is devoted to the structure and strategy of practice (Jørgensen, 2009). For the most dedicated music students, this means that a large proportion of their waking hours is spent on an activity that is relatively unguided and ill-defined (Barry \& Hallam, 2002; Jørgensen, 2000; Renwick \& McPherson, 2002)

As with any other setting, motivation and engagement in learning music at university depends on the learning environment. Learning is challenging for university music students if their environment is not conducive to effective motivation and engagement. In music at university level, particularly in conservatories and classical performance-based degree programs, research suggests that the studio music environment is often not optimal for student motivation. Studio teaching often adopts a demanding, directive, and controlling style (Creech \& Gaunt, 2013; Gaunt, 2011). Even though they may not intend to, teachers can easily dominate lessons by talking and issuing technical demands, with little input from the student (Bonneville-Roussy, Vallerand, \& Bouffard, 2013; Burwell, 2015; Young, Burwell, \& Pickup, 2003). This style of teaching can probably be attributed to the master-apprentice relationship that has long been a tradition (Jørgensen, 2000), with its roots possibly in the boom of the industrial revolution, where printed method books proliferated, instrument ownership became commonplace, and the music studio teaching industry flourished (Gellrich \& Parncutt, 1998).

Evidence suggests that this authoritarian approach to teaching may be problematic for students' motivation to practice. In school settings, a controlling teaching style—one that is directive, where the teacher talks and the student listens, and in which students do not feel any autonomyresults in less student engagement, less deep learning, and less creativity (Niemiec \& Ryan, 2009; Reeve, 2009; Su \& Reeve, 2010). This finding is consistent in other domains such as parent-child relationships (Grolnick, 2003, 2009), health care (Ng et al., 2012), and work relationships (Gagné \& Deci, 2005). Learning more about whether this finding applies to the music learning context is therefore important (Evans, 2015).

Our aim with the present study was to better understand this issue by studying hawhow university music students are motivated, and how motivation affects three aspects of their practice: (1) how often they practice (practice frequency); (2) how often they practice in a way that they perceive to be highly productive or rewarding (quality practice frequency), and (3) their preference for $\underline{\text { choosing challenging tasks above tasks that are easy and within their ability (preference for challenge). }}$ 
the motivation of university music students can affect the quality of their musical practice. We examined music student's motivation in the context of music learning and playing.Self-determination theory (SDT) formed the theoretical approach to our understanding of students' motivation. SDT's central claims are that people's behaviour, engagement, and wellbeing are products of the quality of their interactions with the social environment (Ryan \& Deci, 2000). This study instantiates a broader endeavour to understand the conditions in the social environment that are needed for students to experience wellbeing, aspire to learn, and fulfil their potential for performance excellence.

\section{Practice}

Practice is one of the crucial learning activities for university music students. Music students are often required to do large amounts of practice in order to attain technical and musical expertise, become proficient on their instrument, and reach a standard that allows them to pursue a career in music performance. The most successful musicians know that deliberate practice-effortful, strategic, conscious practice-is necessary to produce reliable and consistent improvements in performance (Barry \& Hallam, 2002). Yet sustaining large amounts of deliberate practice is inherently difficult, and the motivation required for it is complex (Evans, 2015). Much like in other domains, deliberate practice in music is not usually inherently enjoyable in and of itself (Ericsson, Krampe, \& TeschRömer, 1993). It occurs mostly in social isolation, is cognitively demanding, and requires consistent attention and focus.

The deliberate practice framework Ericsson et al. (1993) has been accepted as the primary explanation for expert performance for the last two decades. It is based on the finding of substantially higher accumulations of deliberate practice among expert performers compared with non-experts-a finding initially made with university music students. Some debate has arisen in recent years with the suggestion that deliberate practice may not account for as much variance as the deliberate practice approach claims. For example, recent re-analyses of data from a number of studies found that deliberate practice accounted for only around $30 \%$ of the variance in performance ability, leaving $70 \%$ of the variance explainable by other factors (Hambrick, Altmann, Oswald, Meinz, \& Gobet, 2014). Another study found an average correlation between deliberate practice and performance of only around .35 (Macnamara, Hambrick, \& Oswald, 2014). Bonneville-Roussy and Bouffard (2014) also found that formal practice explained $18 \%$ of the musical achievement of college music students. Ericsson defended these challenges (Ericsson, 2014a, 2014b) stating that the deliberate practice framework is relevant only to expertise, not other types of performance, and that the criteria for including studies in the Macnamara et al. meta-analysis were too broad.

The debate highlights the need to understand more fully the nature of practice and its relationship with performance ability. Nevertheless, there can be no doubt that deliberate practice accounts for a substantial proportion of variance in expert performance and in performance more generally. There appears to be little doubt that deliberate practice is an absolutely necessary activity for developing expertise in the training of musicians at the university level. In addition, the debate 


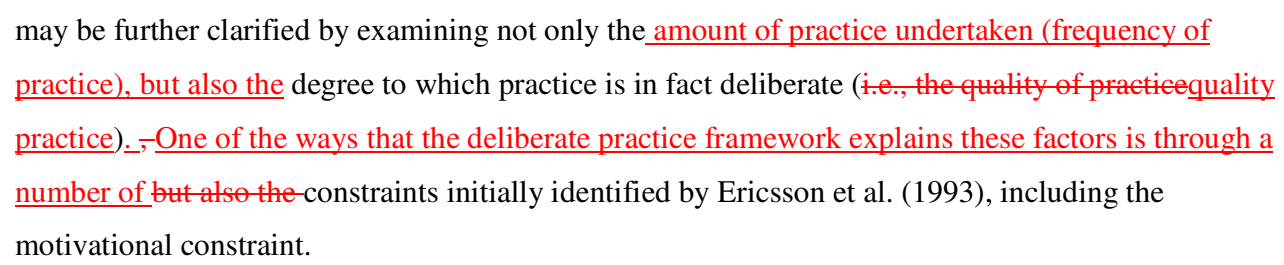

\section{Motivation to Practice}

When Ericsson et al. (1993) outlined their deliberate practice framework, they explained that not all people can easily accumulate the many hours of practice that appear necessary to attain expertise. They identified three 'constraints' on the attainment of such a large number of hours of practice. The effort constraint restricts the ability of a person to maintain full attention for sustained amounts of time; the resources constraint limits access to equipment, access to specialist teachers, transportation to lessons, and training facilities; and the motivational constraint is based on the assumption that "deliberate practice is not inherently enjoyable, and that individuals are motivated to engage in it by its instrumental value in improving performance" (Ericsson et al., 1993, p. 371). The motivation construct is the focus of the present research. Understanding the circumstances under which practice may be experienced as enjoyable or not, and the extent to which people understand the instrumental value of practice in improving performance, would help universities, teachers, and students to create optimal practice environments.

Motivation is therefore important to study because it constraints the amount of practice people are able to undertake. But it is also important to study because it influences behaviours other than practice. People's motivational beliefs_-including beliefs about abilities, beliefs about whether certain activities are useful in attaining goals, and beliefs about why people do what they do-play a substantial role in guiding their behaviours. Motivation also accounts for affective states, psychological wellbeing, the development of personal identity and sense of self, and the resilience and determination to confront and overcome challenges, all of which are important to musicians. One of the most prominent theories in motivation in recent years-self-determination theory-broadly addresses these facets of human life and has been applied to domains such as education, work, sports, personal relationships, and physical and psychological health (Ryan \& Deci, 2000). It is a useful framework for understanding motivation for learning music and its relationships with practice and wellbeing (Evans, 2015).

\section{Self-Determination Theory}

Self-determination theory (SDT) is an approach to human motivation that describes the social circumstances under which people experience wellbeing and vitality. Research in SDT began with research on one of the most consistent distinctions in the study of motivation: that between intrinsic and extrinsic motivation (Deci, 1971). These constructs are relatively agreed upon across the motivation literature: Intrinsic motivation is doing an activity for its own sake and because it is enjoyable or interesting, such as playing one's favourite, learned piece of music for pleasure; while 
extrinsic motivation is doing an activity because of some goal other than the activity itself, for example, to get a good grade, to avoid some kind of punishment, or because it is important in attaining some other goal. Within SDT, extrinsic motivation is further elaborated, with four different regulatory types, from relatively external to the self to relatively internal and aligned with the self (Ryan \& Deci, 2000). For example, relatively external regulations (viz., extrinsic and introjected regulation) could be a teacher or parent telling you what to do, the possibility of a good grade, the avoidance of feeling guilty. Relatively internal regulations (viz., identified and integrated regulation) could be the understanding of how important a task is to achieving other goals or seeing that the task is an important part of who you are, or seeing a task as useful to attaining some other personally important goal. While these regulations are considered extrinsic motivation, they are aligned with one's interests and goals, so their behaviours are considered by SDT as being relatively internal. The more important distinction in SDT, therefore, is the alignment of activities with one's sense of self, rather than whether the activity is intrinsically or extrinsically motivated. In SDT, relatively internal regulations are considered to be more autonomous forms of motivation than relatively external regulations.

Autonomous motivation is fuelled by the fulfilment of basic psychological needs. According to SDT, there are three basic psychological needs which, when fulfilled, provide nutriments for growth, vitality, and wellbeing (Deci \& Ryan, 2000). The needs comprise the need to feel effective and able in one's efforts and in interacting with the social environment (competence), the need to feel accepted and connected by others in social networks (relatedness), and the need to feel as though one's actions are aligned with one's sense of self (autonomy). When people's psychological needs are fulfilled within a domain-such as music learning, they experience the domain as more enjoyable, they engage in activities with meaning and purpose, and they experience wellbeing in domain-related contexts.(For a fuller of

In ether demains domains related to music learning, the SDT framework is supported by a wealth of evidence. In education, for example, studies have found that when teachers are autonomy supportive and provide structure, their students are more engaged (Jang, Reeve, \& Deci, 2010), and when they are more controlling, their students suffer (Soenens, Sierens, Vansteenkiste, Dochy, \& Goossens, 2012). Another consistent finding is that intrinsic motivation is associated with academic achievement (for a recent review and meta-analysis, see Taylor et al., 2014). In countless applied domains, SDT research shows that psychological needs fulfilment and internalised forms of motivation explain more autonomous, healthy forms of functioning and account for substantial variance in outcomes such as creativity, deep learning, wellbeing, passion, and growth. The sheer weight of this evidence, combined with the preliminary work in music education cited above, eompelled us to examine whether this approach could further our understandings about the nature of music learning and practice. The present study therefore adds to a large number of domains in which SDT has been applied. 
In music, $r$ Researchers have begun to explore SDT's applications in music education. In one study, psychological needs fulfilment in children and adolescents waswere more fulfilled when they were highly engaged in their music learning than, and thwarted-at the time they ceased music learning activities (Evans, McPherson, \& Davidson, 2012). One of these children was observed in a qualitative study to use more sophisticated practice strategies in her practice when she had autonomously self-selected her repertoire (Renwick \& McPherson, 2002). In another study, different types of motivation regulation in children were associated with practice behaviours-effort management, monitoring, and strategy use - and motivated students to prepare for performance examinations in different ways (Renwick \& Reeve, 2012). In university students, Bonneville-Roussy et al. (2013) showed that autonomy support from music teachers led to more harmonious passion and ultimately to greater persistence in music education whereas controlling behaviours from teachers were not linked to persistence. (For a fullerconceptual overview of SDT in music education, see Evans, 2015). No study, to our knowledge, has yet examined university students' practice quantity or practice quality using self-determination theory.

\section{The present study}

The aim of the present study was to test, within a SDT theoretical framework, how the perception of needs satisfaction from the music learning environment can shape university music students' motivation towards music, and, in turn, the frequency and quality of their practice. Past research has shown that satisfaction of the needs for autonomy, competence, and relatedness promote more self-determined forms of motivation (Deci \& Ryan, 2000; Hagger, Chatzisarantis, \& Harris, 2006). Therefore, we hypothesized that music students who perceived that their psychological needs | were satisfied by their musical environment would have more autonomous motivation towards music. In addition, past research in other educational areas has found that autonomous motivation is linked to better engagement, persistence and overall academic success (Deci, Vallerand, Pelletier, \& Ryan, 1991; Niemiec \& Ryan, 2009). In the present study, three aspects of practice behaviour were examined: the frequency of practicepractice frequency, the frequency of quality practicequality practice frequency (i.e., how often practice that was productive or rewarding), and preference for challenge-the degree to which students preferred to set themselves challenges that exceeded their ability but were within reach, as compared with choosing tasks that were comfortable and well within their ability. In line with past research, we hypothesized that more autonomous motivation would lead to higher practice frequencymore frequent practice, better higher quality practice frequency, and higher preference for challenge. We tested these hypotheses using structural equation modelling.

\section{Method}

\section{Participants}

Participants were 410 university music students from nine schools of music at universities in Australia and New Zealand. Students were enrolled in undergraduate music degree programs in which music performance is a core requirement, and in which students receive regular studio tuition. There 
were $146(36 \%)$ males, $256(63 \%)$ females, and 3 selected 'other' or chose not to respond. The mean age was 21.61 years $(S D=5.49)$. The participants completed the consent process and the survey online. Administrators in each of the nine universities were asked to forward a link to the online survey to all students in undergraduate music programs that had performance as a substantial component.

\section{Measures}

Psychological needs satisfaction. Competence, relatedness, and autonomy were measured based on the Balanced Measure of Psychological Needs (BMPN; Sheldon \& Hilpert, 2012). In this scale, the needs are measured using three positively-worded and three negatively-worded items each, resulting in 18 items (only the positively-worded items were used in the present study to examine psychological needs satisfaction). Participants responded to each item on a 7-point scale from "not at all true" to "very true." To measure the needs in the intended context, the stem "In my music learning and playing, ..." was stated before the set of 18 items. The BMPN is a domain-general measure of psychological needs, so minor changes to some item wordings were made so that the items were appropriate to the context (e.g., "I successfully learn difficult things" was adapted to "I successfully learn difficult music"). We refer to this adapted instrument as BMPN-Music throughout this paper, and its items are listed in Appendix 1.

Autonomous Motivation. Measures were adapted from Ryan and Connell's (1989) widelyused measures of these types of motivation in academic settings, the self-regulation questionnaire (SRQ); we refer to our minor adaptation as SRQ-Music throughout this paper and its items are listed in Appendix 1. Two blocks of items were presented, with the stems "Why do you play and learn music?" and "Why do you have music lessons?" respectively. In each block, four types of motivation regulation were measured, ranging from relatively external to relatively internal regulation, by two items each: extrinsic regulation (e.g., "because I am supposed to"), introjected regulation (e.g., "so I can show off my abilities"), identified regulation (e.g., "because I wanted to be a good musician"), and intrinsic motivation (e.g., "because I love playing my instrument"). These items were parcelled and used as indicators of a single latent variable named 'autonomous motivation' (see Results section).

Practice Frequency. Participants were asked "How many times have you practiced on your instrument in the last 7 days (do not include lessons)?" to measure the frequency of their practice.

Quality Practice Frequency. We assessed practice quality using a single item, "How many of your practice sessions in the last 7 days were really productive or rewarding?"

Preference for Challenge. We asked participants to respond to the item, "Next time I select a new piece of music to play, it will be..." on a 7-point scale from "well within my ability" to "challenging and above my ability".

Affect. We asked participants how much they felt 4 affective states in their music learning and playing — happy, unhappy, proud, and guilty—in response to the question, "In my music learning and playing, I feel..." 


\section{Analytical Approach}

\section{Results}

We addressed the aims of this project within the analytical framework of structural equation modelling (SEM). SEM is a statistical method that aims at measuring the relationship between a set of variables and assessing causal relationships between constructs. It uses model fit indices to evaluate whether the modelled relationships between variables are a meaningful representation of the data. Confirmatory factor analysis (CFA) in the SEM framework has several advantages compared with traditional exploratory factor analysis (Brown, 2006; Muthén \& Muthén, 2010). First, model fit indices allow researchers to assess whether the number of factors retained in a given analysis provides appropriate fit to the data. Second, it provides a standard error of means for the observed variables. This allows researchers to test the significance of an observed variable on a latent construct. Measurement models in SEM also provide error variances of observed variables that indicate the amount of unexplained variance. Finally, CFA tests for more stringent, theory-driven measurement models, as the observed variables are hypothesized to be represented by only one factor.

In our analyses, model goodness-of-fit was evaluated according to the recommendations of Marsh et al. (2009). That is, a model was deemed to have acceptable fit with a comparative fit index (CFI) equal to or higher than .90 (and an excellent fit equal to or greater than .95) and a root mean square error of approximation (RMSEA) and standardized root mean square residuals (SRMR) equal to or less than .08 (or less than .05 for an excellent fit). The issue of chi-square has been debated. Traditionally, it has been argued that non-significance of chi-square should be met; however, as chisquare indices are inflated by sample sizes and model complexity (number of degrees of freedom), they are more likely to be significant when larger sample sizes are used and when the model has a high degree of complexity (Brown, 2006; Kline, 2010). Therefore, in this work, chi-square statistics are interpreted with caution.

In the approach to the present study, we took advantage of SEM in several ways. First, we performed two CFAs to confirm the validity of our psychological needs satisfaction and autonomous motivation scales. Based on the results of these CFAs, we then computed variables for needs satisfaction and RAI parcels for use in subsequent analyses. We used a full structural equation model to address our main research objectives. Finally, we present computed factor scores and their correlations with affect variables to more fully understand the relationships between motivation, practice, and affect. All of the analyses were performed using Mplus version 7.3 (Muthén \& Muthén, 2014)

\section{Psychological needs satisfaction scale (BMPN-Music)}

We used a CFA to examine the validity of the three needs satisfaction dimensions (autonomy, competence, and relatedness). Since the BMPN-Music measures the three psychological needs positively and negatively worded items each, we used a second-order CFA to assess, first, the validity of the positive and negative valence of each sub-scale (e.g. autonomy-positively worded and 
autonomy-negatively worded, for a total of six subscales). Then we assessed whether these positive and negative subscales (e.g., competence satisfaction, competence thwarting) formed single latent constructs (e.g. competence) in a second higher-order factor analysis. Results confirmed that the second-order factor analysis fit the data well, $\chi_{125}^{2}=233.42, p<.001, \mathrm{CFI}=.96, \mathrm{TLI}=.95$, $\mathrm{RMSEA}=.05(95 \% \mathrm{CI}=.04-.06), \mathrm{SRMR}=.06$. Standardised loadings on the factors ranged from .51 to .83 for the lower-order sub-scales and varied from -.46 (negative subscale) to 1.00 (positive subscale) for the higher-order dimensions, with all loadings significant at $p<.001$ (specific loading values are available from the corresponding author). These results confirm the validity of the BMPN-Music scale.

Given our sample size limitations, and the requirement for model parsimony, we used measures of the three needs created by summing the individual positively-worded items within each need. The higher-order CFA justified this approach of using composite scores for competence, relatedness, and autonomy.

\section{Autonomous Motivation Scale (SRQ-Music)}

To examine the factor structure of the autonomous motivation scale, we performed a CFA with the 16 SRQ-Music observed variables. These variables have been shown in past research to represent four types of motivation regulation, with four items representing each form of regulation, from relatively internal to relatively external: intrinsic, identified, introjected, and external (Ryan \& Connell, 1989). Results of the CFA confirmed the four-factor structure of the scale, $\chi^{2}{ }_{94}=226.91$, $p<.001, \mathrm{CFI}=.94, \mathrm{TLI}=.93, \mathrm{RMSEA}=.06(95 \% \mathrm{CI}=.05-.07), \mathrm{SRMR}=.06$. Standardized loadings on the factors ranged from .39 to .88 and all were significant at $p<.001$ (specific loadings are available from the corresponding author). These results show that the four types of motivation are well represented by their corresponding items.

In the subsequent structural model, we required a single measure of autonomous motivation to maximise statistical power and to best take advantage of the sample size. To use the SRQ-M items as a single measure of motivation internalisation, we adopted the approach used in previous research (e.g., Niemiec et al., 2006; Ryan \& Connell, 1989) of creating a relative autonomy index (RAI). In the RAI, more weight is put on intrinsic and extrinsic forms of regulation. A higher positive score indicate a more autonomous motivation. Ryan and Connell (1989) first developed the RAI by using weighted measures of each type of regulation, such that:

$$
\text { RAI }=2 \times \text { Intrinsic }+ \text { Identified }- \text { Introjected }-2 \times \text { Extrinsic }
$$

We employed this procedure to create item parcels: Four parcelled RAI indicator variables were computed based on the equation above, selecting one item randomly from each of the four types of extrinsic motivation in the SRQ-Music. In the subsequent structural model, the item parcels were used as indicators of a latent variable, which we named autonomous motivation. 


\section{Descriptive Statistics}

To detect and remove multivariate outliers, we computed the Mahalanobis distance using all variables in the path analysis model below. Mahalanobis distances were standardised, and a total of 8 cases with scores greater than 3 standard deviations from the mean were removed.

Descriptive statistics (M and SD) and correlations for all observed variables are presented in Table 1. Small to moderate correlations were observed, as expected, between practice variables and almost all of the motivation variables used in the following models.

\section{Insert Table 1 about here}

\section{Full SEM of needs satisfaction, autonomous motivation, and musical practice}

Table 2 presents the descriptive statistics and correlation coefficients of the variables included in our main hypothesized model. Because our three measures of practice were skewed, we used the MLR estimator, which computes means and standard errors that are robust to non-normality of the data. The MLR scaling for correction was 1.08 , meaning that only a minor correction was required for this model. Psychological needs satisfaction was modelled as a latent variable indicated by autonomy, competence, and relatedness satisfaction items. Autonomous motivation was modelled as a latent variable indicated by four RAI item parcels.

\section{Insert Table 2 about here}

A first analysis was conducted with psychological needs satisfaction being explained by the autonomy, competence and relatedness needs dimensions. Psychological needs satisfaction predicted autonomous motivation. Finally, autonomous motivation predicted our three practice variables: practice frequency, quality practice frequency, and preference for challenge. The fit indices of this initial model did not meet the threshold of adequacy, $\chi_{33}^{2}=106.28, p<.001$; RMSEA = .08 (.06-.09); $\mathrm{CFI}=.92 ; \mathrm{TLI}=.89 ; \mathrm{SRMR}=.07$. The examination of modification indices revealed that two of the RAI item parcels were significantly related $(\beta=.31, \mathrm{p}<.001)$, and allowing them to covary would significantly increase the fit of our model. This model with an added relationship between two residuals is presented next.

The overall fit information of the final model was adequate, indicating that our data fit the hypothesized links well, $\chi_{32}^{2}=94.08, p<.001$; RMSEA $=.07$ (.05-.09); CFI = .93; TLI = .90; $\mathrm{SRMR}=.06$. This final model is presented in Figure 1. In summary, psychological needs satisfaction was successfully explained by the satisfaction of the needs for autonomy, competence, and relatedness. In addition, autonomous motivation was adequately explained by the four RAI parcelled measures. Autonomous motivation was predicted by psychological needs satisfaction. In turn, autonomous motivation was significantly related to practice frequency, quality practice frequency, 
and preference for challenge, our three measures of practice behaviour. This model explained $6 \%$ of the variance in practice frequency, $11 \%$ of the variance in the frequency of quality practice and $9 \%$ of the variance in preference for challenge.

\section{Insert Figure 1 about here}

We also found indirect effects. The links between needs satisfaction and practice time was significantly mediated by autonomous motivation $(\beta=.13, p<.001)$. Autonomous motivation also mediated the associations between psychological needs satisfaction and quality practice frequency $(\beta=.18, p<.001)$, and preference for challenge $(\beta=.17, p<.001)$.

Affect

While the requirements of a parsimonious model and the limitations of sample size prevented us from including affect variables in the model, we were still able to examine their relations with the latent constructs. We computed factor scores for the latent variables of needs satisfaction and autonomous motivation, and examined correlations between them and practice behaviours (Table 3). Correlations were observed between affect and needs satisfaction and motivation variables, but not between affect and practice behaviour variables. Table 3 shows that needs satisfaction was positively related to feeling happy, relaxed, excited and proud, and negatively related to feeling nervous.

Autonomous motivation was positively linked with feeling happy, excited and negatively linked with proud and unhappy. No relationships were found between affect and practice timpractice frequencye, quality of practice frequency, and preference for challenges.

Insert Table 3 about here

\section{Discussion}

Improving performance ability is amongst the core goals of university music programs, and practice is undoubtedly one of the most important activities for attaining that goal. The present study aimed to model aspects of university music student motivation, and the relationship between motivation and practice frequency, quality practice frequency, and preference for challenge. We confirmed our first hypothesis: Music students who perceived that their psychological needs were satisfied by the music environment would have more autonomous motivation towards music. We also confirmed our second hypothesis: Autonomous motivation predicted practice frequency, quality practice frequency, and preference for challenge. found that greater psychological needs fulfilment was associated with autenomous motivation, which in turn was associated with practice behaviours. This finding is in line with the claim of SDT in which students whose environments fulfil the their basic psychological needs are more autonomously motivated and do better quality practice than those whose environments are not as optimal. Relationships were uncovered not just with the frequency of 
the students' practice, but also the frequency of their practice that was perceived to be more productive, and their preference for choosing challenging learning tasks over easy tasks. They

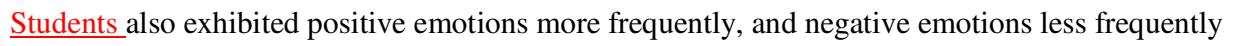
when their psychological needs were fulfilled and when they were autonomously motivated.

This study was motivated by our interests in several strands of literature related to motivation and music education. Our first objective was to use self-determination theory to more fully understand motivation for music learning. While motivation for music learning has been researched in the past from a number of angles, SDT's wider lens enabled us to examining a framework for the perceptions of environments and social relationships that are conducive to excellence, learning, and human flourishing. In musie, researchers havegun to explore SDT. In onestudy, psychogical needs fulfilment in ehildren and alolesents more fulfilled when they were highly engaged in their music learning, and thwated at the time they ceas music leaning activities (Evans, MePherson, \& Davidson, 2012). One of these children was obsed in a qualitativestudy to moresophisticated practice strategies in her practice when she had autonomously self select her repertoire (Renwick \& MePherson, 2002). In another stuly, different types of motivation regulation in ehildren were asolated with pratice behaviours-effort management, monitoring, and strategy use and motivated students toprepare for performanee examinations in different ays (Renwiek \& Reeve,

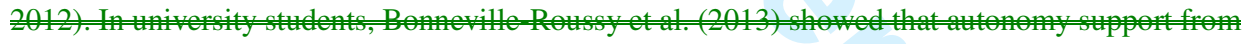
music teachers led to more harmonious passion and ultimately to-greater persistence in music

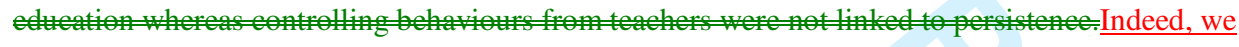
found results that are consistent with the literature on SDT in other areas. Our hypothesis that psychological needs fulfilment in music relates to autonomous motivation reflects findings made by Standage, Duda, and Ntoumanis (Standage, Duda, \& Nteumanis, 2005) in the school physical education context, and also by Niemiec et al., (Niemiec et al.,2006) in the context of college education. The result that autonomy needs satisfaction more strongly predicts autonomous motivation was to be expected, since both aim at increasing or enhancing one's free choices, and is also in line

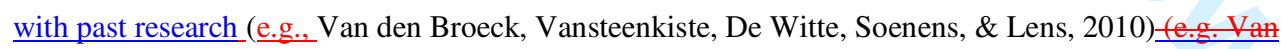
den Broeck et al., 2010). Our hypothesis that autonomous motivation in turn predicts adaptive domain-related behaviours is also supported by research. Standage et al. (2005), for example, found that autonomous motivation positively predicted positive affect, concentration, preference for challenge, and negatively predicted negative affect. Extensive research in school education and other education contexts such as university have demonstrated that psychological needs support in these contexts produces greater wellbeing, engagement, and achievement (for reviews see Niemiec \& Ryan, 2009; Reeve \& Halusic, 2009).

In other domains, the SDT framework is supported by a alth of evidenee. In edueation, for example, studies have found that when teachers are autonomy supportive and providestuetue, their

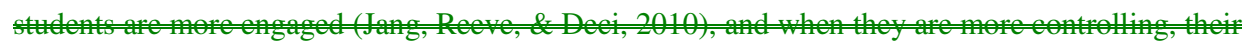




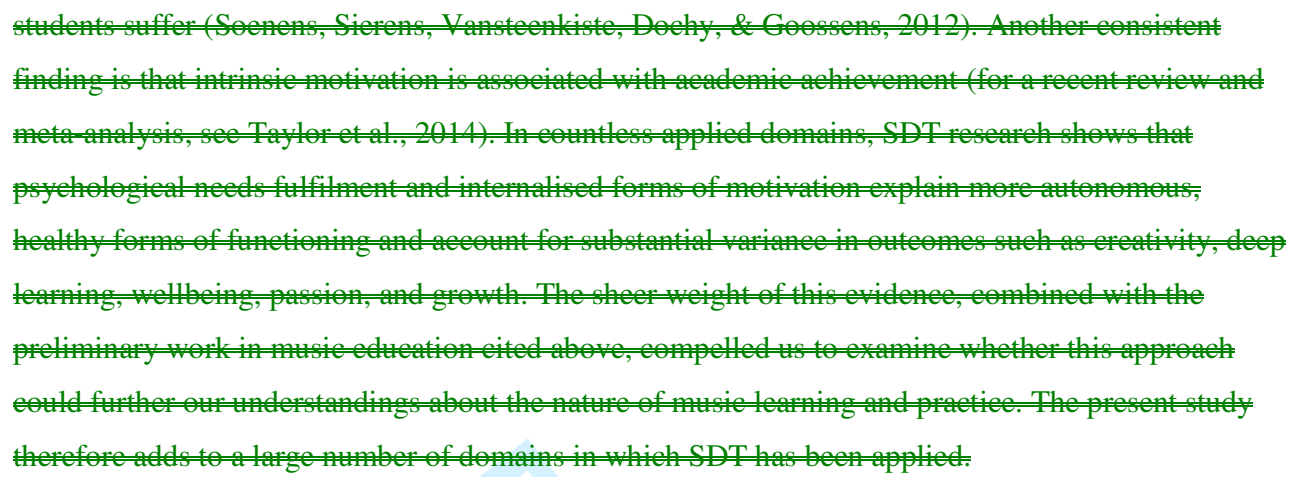

SDT also appealed to us because there is a clear path towards developing interventions that might be able to improve student motivation and performance outcomes. In educational settings, intervention studies have found that teachers are easily able to learn about how to provide autonomy support and structure within their school classrooms, and when they do, their students experience better feelings of autonomy, greater engagement, and better learning (e.g., Kiemer, Gröschner, Pehmer, \& Seidel, 2015; Peetsma \& Van der Veen, 2013; Ratelle \& Duchesne, 2014; Reeve \& Lee, 2014; for a meta-analysis see Su \& Reeve, 2010). University tutors have participated in seminars to learn about autonomy support, and subsequently shown more autonomy-supportive behaviours in their classrooms (McLachlan \& Hagger, 2010). With some further research on SDT in the domain of music learning, it is foreseeable that intervention studies in which university studio teachers may be empowered to provide autonomy-supportive learning environments for their students, and see increases in the productivity of their students' practice, wellbeing, and approach to challenge. Indeed, Gaunt (2011) observed viable alternatives to the standard one-on-one arrangement in her study where students had several teachers, and as a result, felt a greater sense of autonomy. Potential ways to improve needs support specifically in the context of instrumental music studios are made by Evans (Evans, 2015) and although these remain to be empirically examined, the results of research in other domains is promising. Further research is needed to examine the viability of such an arrangement, but this example demonstrates that alternatives to the standard, master-apprentice model may result in better feelings of autonomy.

We prefaced our introduction to this study by situating the importance of music practice within the deliberate practice framework. Deliberate practice as an explanation for expertise is currently under considerable scrutiny, in light of increasing evidence of the contribution of genetic factors to explaining variance in performance. As previously noted, these issues continue to be debated, with some researchers arguing that the emphasis placed on deliberate practice is not justified because the proportion of variance it explains in performance is too low (Hambrick et al., 2014). Others, using more precise definitions of both expertise and deliberate practice, maintain that substantial evidence still exists for deliberate practice as the primary explanation for why some people become experts and others do not (Ericsson, 2014b; Platz, Kopiez, Lehmann, \& Wolf, 2014). 


\begin{abstract}
Regardless of these points of view, practice is the primary activity that is within the student's control for improving performance ability, so its importance as a learning activity for university music students cannot be underrated. Our findings have demonstrated that self-determined motivation and practice are indeed connected, and they suggest that students who are more motivated practice more, and that their practice is more productive. We look forward to the next logical step in this research program, which might uncover how this then relates to progress in students' performance abilities, including using more precise measures of both the quality and quantity of practice. Such research could contribute substantially to the present debate around deliberate practice and expert performance. We acknowledge some limitations of this study. First, it is difficult to interpret the specific aspects of the environment that affected students' fulfilment of psychological needs and autonomous motivation. We asked students about these aspects of their motivation at the general domain levelthe context of their music learning and playing. The response is therefore an amalgamation of the overall aspects of students' engagement with the overall musical domain—studio lessons, their other university classes, their informal music experiences.-Further research could measure motivation within more specific situations (e.g., studio teaching) in order to more precisely isolate aspects for which it is feasible to intervene and improve motivation. Second, the total variance explained in our outcome variables (practice frequency, quality practice frequency, and preference for challenge) was not high. We did not expect these $\mathrm{R}^{2}$ values to be high, since our aim with this study was not to comprehensively model these outcome variables of practice quantity and quality. Rather, our focus was on modelling motivation, and using the outcome variables to examine structural relations. In relation to the first point, if we had used more proximal measures of motivation (e.g., needs fulfilment while practising; autonomous motivation in the context of the activity of music practice) we may have seen a greater amount of variance accounted for in the outcomes. In addition, further predictive variables related to practice frequency (e.g., Ericsson's effort and resource constraints outlined in the Introduction) and other constructs related to quality practice frequency (e.g., self-regulated learning; McPherson \& Renwick, 2011) would increase the variance explained by the practice variables examined here. Having stated this, however, it is important to note that in practical terms, teachers may be substantially interested in any increase in variance of these behaviours that they can encourage in students. Changing teacher behaviour to be more supportive of psychological needs is relatively easy and low-cost for teacher (e.g., McLachlan \& Hagger, 2010; Su \& Reeve, 2010), so there is obvious practical significance of this finding even though the variance accounted for might otherwise be considered low.
\end{abstract}

Another limitation is the accuracy of measures of practice, which is an ongoing issue, and one of the major keys to refining the deliberate practice debate. Retrospective measures of practice over large periods of time can be terribly inaccurate. For this reason, we asked students specifically about the last 7 days of practice, hoping that this recent window would result in a more accurate self-report. Yet it is difficult to tell whether this worked, and the approach also relies on the assumption that the 
last 7 days was an indicative sample of the average amount of practice the student normally does. Because it seems to be an important variable, future research may examine the viability of experience sampling methods or other means of more accurately and precisely accounting for practice. More developed research methods may also account for different types of practice-conscious, deliberate practice, drilling and technical exercises, and informal play—and thus account for the respective contributions of each type of practice to motivation and performance ability. Such future research could also overcome the present study's sample size limitation.

\section{Conclusion}

Clear evidence already exists to show that practice is important to university music student success. It is also well-known that motivation is a critical issue for maintaining practice. This study goes part of the way to address a self-determination theory research agenda connecting the needs fulfilment in the social environment to internalised motivation, and in turn, to practicepractice frequency, quality practice frequency, stecess,preference for challenge, and psychological well-being. We look forward to future research examining these aspects of music learning in more detail, particularly in relation to refining which types of practice make a difference, and studying these aspects of music learning in relation to performance ability. 


\section{References}

Barry, N., \& Hallam, S. (2002). Practice. In R. Parncutt \& G. E. McPherson (Eds.), The science and psychology of music: Creative strategies for teaching and learning (pp. 151-165). Oxford, England: Oxford University Press.

Bennett, D., \& Stanberg, A. (2008). Musicians as teachers: Fostering a positive view. In D. Bennett \& M. Hannan (Eds.), Inside, outside, upside down: Conservatoire training and musicians' work (pp. 11-22). Perth, Australia: Black Swan Press.

Bonneville-Roussy, A., \& Bouffard, T. (2014). When quantity is not enough: Disentangling the roles of practice time, self-regulation and deliberate practice in musical achievement. Psychology of Music. doi:10.1177/0305735614534910

Bonneville-Roussy, A., Vallerand, R. J., \& Bouffard, T. (2013). The roles of autonomy support and harmonious and obsessive passions in educational persistence. Learning and Individual Differences, 24, 22-31. doi:10.1016/j.lindif.2012.12.015

Brown, T. A. (2006). Confirmatory factor analysis for applied research. New York, NY: Guilford.

Burwell, K. (2015). "She did miracles for me": An investigation of dissonant studio practices in higher education music. Psychology of Music, Advance online publication. doi:10.1177/0305735615576263

Creech, A., \& Gaunt, H. (2013). The changing face of individual instrumental tuition: Value, purpose, and potential. In G. E. McPherson \& G. Welch (Eds.), Oxford handbook of music education (pp. 694-711). Oxford, England: Oxford University Press.

Deci, E. L. (1971). Effects of externally mediated rewards on intrinsic motivation. Journal of Personality and Social Psychology, 18, 105-115. doi:10.1037/h0030644

Deci, E. L., \& Ryan, R. M. (2000). The "What" and "Why" of Goal Pursuits: Human Needs and the Self-Determination of Behavior. Psychological Inquiry, 11, 227-268. doi:10.1207/S15327965PLI1104_01

Deci, E. L., Vallerand, R. J., Pelletier, L., \& Ryan, R. M. (1991). Motivation and Education: The SelfDetermination Perspective. Educational Psychologist, 26, 325-346. doi:10.1207/s15326985ep2603\&4_6

Ericsson, K. A. (2014a). Challenges for the estimation of an upper-bound on relations between accumulated deliberate practice and the associated performance of novices and experts: Comments on Macnamara, Hambrick, and Oswald's (2014) published meta analysis. (Rejected reply to Macnamara et al. in Psychological Science, 2014). Retrieved from https://psy.fsu.edu/faculty/ericsson/ericsson.hp.html

Ericsson, K. A. (2014b). Why expert performance is special and cannot be extrapolated from studies of performance in the general population: A response to criticisms. Intelligence, 45, 81-103. doi:10.1016/j.intell.2013.12.001 
Ericsson, K. A., Krampe, R. T., \& Tesch-Römer, C. (1993). The role of deliberate practice in the acquisition of expert performance. Psychological Review, 100, 363-406. doi:10.1037/0033295X.100.3.363

Evans, P. (2015). Self-determination theory: An approach to motivation in music education. Musicae Scientiae, 19, 65-83. doi:10.1177/1029864914568044

Evans, P., McPherson, G. E., \& Davidson, J. W. (2012). The role of psychological needs in ceasing music and music learning activities. Psychology of Music, 41, 600-619. doi:10.1177/0305735612441736

Gagné, M., \& Deci, E. L. (2005). Self-determination theory and work motivation. Journal of Organizational Behavior, 26, 331-362. doi:10.1002/job.322

Gaunt, H. (2011). Understanding the one-to-one relationship in instrumental/vocal tuition in Higher Education: comparing student and teacher perceptions. British Journal of Music Education, 28, 159-179. doi:10.1017/S0265051711000052

Gellrich, M., \& Parncutt, R. (1998). Piano technique and fingering in the eighteenth and nineteenth centuries: Bringing a forgotten method back to life. British Journal of Music Education, 15, 523.

Grolnick, W. S. (2003). The psychology of parental control: How well-meant parenting backfires. Hillsdale, NJ: Lawrence Erlbaum Associates.

Grolnick, W. S. (2009). The role of parents in facilitating autonomous self-regulation for education. Theory and Research in Education, 7, 164-173. doi:10.1177/1477878509104321

Hagger, M. S., Chatzisarantis, N. L. D., \& Harris, J. (2006). From psychological need satisfaction to intentional behavior: testing a motivational sequence in two behavioral contexts. Personality and Social Psychology Bulletin, 32, 131-148. doi:10.1177/0146167205279905

Hambrick, D. Z., Altmann, E. M., Oswald, F. L., Meinz, E. J., \& Gobet, F. (2014). Facing facts about deliberate practice. Frontiers in Psychology, 5, 751. doi:10.3389/fpsyg.2014.00751

Jang, H., Reeve, J., \& Deci, E. L. (2010). Engaging students in learning activities: It is not autonomy support or structure, but autonomy support and structure. Journal of Educational Psychology, 102, 588-600. doi:10.1037/a0019682

Jørgensen, H. (2000). Student learning in higher instrumental education: who is responsible? British Journal of Music Education, 17, 67-77. doi:10.1017/S0265051700000164

Jørgensen, H. (2009). Practising. In S. Hallam, I. Cross, \& M. Thaut (Eds.), Oxford Handbook of Music Psychology (pp. 265-273). Oxford, England: Oxford University Press.

Kiemer, K., Gröschner, A., Pehmer, A.-K., \& Seidel, T. (2015). Effects of a classroom discourse intervention on teachers ' practice and students ' motivation to learn mathematics and science, 35, 94-103. doi:10.1016/j.learninstruc.2014.10.003

Kline, R. B. (2010). Principles and practice of structural equation modeling (3rd ed.). New York: Guilford. 
Macnamara, B. N., Hambrick, D. Z., \& Oswald, F. L. (2014). Deliberate practice and performance in music, games, sports, education, and professions: a meta-analysis. Psychological Science, 25, 1608-1618. doi:10.1177/0956797614535810

Marsh, H. W., Muthén, B., Asparouhov, T., Lüdtke, O., Robitzsch, A., Morin, A. J. S., \& Trautwein, U. (2009). Exploratory structural equation modeling, integrating CFA and EFA: Application to students' evaluations of university teaching. Structural Equation Modeling: A Multidisciplinary Journal, 16, 439-476. doi:10.1080/10705510903008220

McLachlan, S., \& Hagger, M. S. (2010). Effects of an autonomy-supportive intervention on tutor behaviors in a higher education context. Teaching and Teacher Education, 26, 1204-1210. doi:10.1016/j.tate.2010.01.006

McPherson, G. E., \& Renwick, J. M. (2011). Self-Regulation and Mastery of Musical Skills. In B. J. Zimmerman \& D. H. Schunk (Eds.), Handbook of self-regulation of learning and performance (pp. 234-248). New York: Routledge.

Muthén, L. K., \& Muthén, B. O. (2010). Chapter 5. Examples: confirmatory factor analysis and structural equations. In Mplus: Statistical analysis with latent variables: User's guide Version 7 (pp. 55-110). Retrieved from http://www.statmodel.com/ugexcerpts.shtml

Muthén, L. K., \& Muthén, B. O. (2014). MPlus version 7.3 [computer software]. Muthén and Muthén. Retrieved from http://statmodel.com

Ng, J., Ntoumanis, N., Thøgersen-Ntoumani, C., Ryan, R. M., Duda, J. L., \& Williams, G. C. (2012). Self-determination theory applied to health contexts: A meta-analysis. Perspectives on Psychological Science, 7, 325-340. doi:10.1177/1745691612447309

Niemiec, C. P., Lynch, M. F., Vansteenkiste, M., Bernstein, J., Deci, E. L., \& Ryan, R. M. (2006). The antecedents and consequences of autonomous self-regulation for college: A selfdetermination theory perspective on socialization. Journal of Adolescence, 29, 761-775. doi:10.1016/j.adolescence.2005.11.009

Niemiec, C. P., \& Ryan, R. M. (2009). Autonomy, competence, and relatedness in the classroom: Applying self-determination theory to educational practice. Theory and Research in Education, 7, 133-144. doi:10.1177/1477878509104318

Peetsma, T., \& Van der Veen, I. (2013). Influencing young adolescents' motivation in the lowest level of secondary education. Educational Review, (February 2015), 1-24. doi:10.1080/00131911.2013.830593

Platz, F., Kopiez, R., Lehmann, A. C., \& Wolf, A. (2014). The influence of deliberate practice on musical achievement: A meta-analysis. Frontiers in Psychology, 5, 1-13. doi:10.3389/fpsyg.2014.00646

Ratelle, C. F., \& Duchesne, S. (2014). Trajectories of psychological need satisfaction from early to late adolescence as a predictor of adjustment in school. Contemporary Educational Psychology, 39, 388-400. doi:10.1016/j.cedpsych.2014.09.003 
Reeve, J. (2009). Why Teachers Adopt a Controlling Motivating Style Toward Students and How They Can Become More Autonomy Supportive. Educational Psychologist, 44, 159-175. doi:10.1080/00461520903028990

Reeve, J., \& Halusic, M. (2009). How K-12 teachers can put self-determination theory principles into practice. Theory and Research in Education, 7, 145-154. doi:10.1177/1477878509104319

Reeve, J., \& Lee, W. (2014). Students' classroom engagement produces longitudinal changes in classroom motivation. Journal of Educational Psychology, 106, 527-540. doi:10.1037/a0034934

Renwick, J. M., \& McPherson, G. E. (2002). Interest and choice: student-selected repertoire and its effect on practising behaviour. British Journal of Music Education, 19, 173-188. doi:10.1017/S0265051702000256

Renwick, J. M., \& Reeve, J. (2012). Supporting motivation in music education. In G. E. McPherson \& G. Welch (Eds.), Oxford Handbook of Music Education, Volume 1 (pp. 143-162). Oxford, England: Oxford University Press. doi:10.1093/oxfordhb/9780199730810.001.0001

Ryan, R. M., \& Connell, J. P. (1989). Perceived locus of causality and internalization: Examining reasons for acting in two domains. Journal of Personality and Social Psychology, 57, 749-761.

Ryan, R. M., \& Deci, E. L. (2000). Self-determination theory and the facilitation of intrinsic motivation, social development, and well-being. American Psychologist, 55, 68-78.

Sheldon, K. M., \& Hilpert, J. C. (2012). The balanced measure of psychological needs (BMPN) scale: An alternative domain general measure of need satisfaction. Motivation and Emotion, 36, 439451. doi:10.1007/s11031-012-9279-4

Soenens, B., Sierens, E., Vansteenkiste, M., Dochy, F., \& Goossens, L. (2012). Psychologically controlling teaching: Examining outcomes, antecedents, and mediators. Journal of Educational Psychology, 104, 108-120. doi:10.1037/a0025742

Standage, M., Duda, J. L., \& Ntoumanis, N. (2005). A test of self-determination theory in school physical education. The British Journal of Educational Psychology, 75, 411-433. doi:10.1348/000709904X22359

Su, Y.-L., \& Reeve, J. (2010). A Meta-analysis of the Effectiveness of Intervention Programs Designed to Support Autonomy. Educational Psychology Review, 23, 159-188. doi:10.1007/s10648-010-9142-7

Taylor, G., Jungert, T., Mageau, G. A., Schattke, K., Dedic, H., Rosenfield, S., \& Koestner, R. (2014). A self-determination theory approach to predicting school achievement over time : the unique role of intrinsic motivation. Contemporary Educational Psychology, 39, 342-358. doi:10.1016/j.cedpsych.2014.08.002

Van den Broeck, A., Vansteenkiste, M., De Witte, H., Soenens, B., \& Lens, W. (2010). Capturing autonomy, competence, and relatedness at work: Construction and initial validation of the Work-related Basic Need Satisfaction scale. Journal of Occupational and Organizational Psychology, 83, 981-1002. doi:10.1348/096317909X481382 


\section{Page 19 of 25}

Psychology of Music

1
1
3
4
5
6
7
8
9
10
11
12
13
14
15
16
17
18
19
20
21
22
23
24
25
26
27
28
29
30
31
32
33
34
35
36
37
38
39
40
41
42
43
44
55
50
56
57
48
59
50
51
53
50

Young, V., Burwell, K., \& Pickup, D. (2003). Areas of Study and Teaching Strategies Instrumental Teaching: a case study research project. Music Education Research, 5, 139-155. doi:10.1080/1461380032000085522 
Table 1: Descriptive statistics and correlation coefficients of the observed and parcelled variables included in this study

\begin{tabular}{|c|c|c|c|c|c|c|c|c|c|c|c|}
\hline Variables & Mean & SD & $\overline{1}$ & 2 & 3 & 4 & 5 & 6 & 7 & 8 & 9 \\
\hline 1. Practice Frequency & 5.64 & 2.38 & - & & & & & & & & \\
\hline 2. Quality Practice Frequency & 3.86 & 1.97 & $.82 *$ & - & & & & & & & \\
\hline 3. Preference for Challenge & 5.08 & 2.25 & $.23^{*}$ & $.31^{*}$ & - & & & & & & \\
\hline 4. Competence & 14.88 & 3.86 & $.12 *$ & $.19^{*}$ & $.39^{*}$ & - & & & & & \\
\hline 5. Relatedness & 14.47 & 3.80 & .04 & .09 & $.17 *$ & $.26^{*}$ & - & & & & \\
\hline 6. Autonomy & 16.32 & 4.04 & .07 & $.15^{*}$ & $.22 *$ & $.39^{*}$ & $.42 *$ & - & & & \\
\hline 7. RAI1 & 11.53 & 3.40 & $.15^{*}$ & $.22 *$ & $.20 *$ & $.19^{*}$ & $.18^{*}$ & $.33^{*}$ & - & & \\
\hline 8. RAI2 & 10.49 & 3.24 & .10 & $.18^{*}$ & $.15^{*}$ & $.20^{*}$ & $.15^{*}$ & $.26^{*}$ & $.62 *$ & - & \\
\hline 9. RAI3 & 9.28 & 3.05 & $.16^{*}$ & $.19^{*}$ & $.18^{*}$ & $.19^{*}$ & .10 & $.26^{*}$ & $.50^{*}$ & $.48^{*}$ & - \\
\hline 10. RAI4 & 9.30 & 3.05 & $.21 *$ & $.25^{*}$ & .09 & $.17 *$ & $.14^{*}$ & $.32 *$ & $.42 *$ & $.47 *$ & $.49^{*}$ \\
\hline
\end{tabular}

Note: $N=392 ;{ }^{*} p<.01$. RAI $=$ Relative Autonomy Index 


\section{Page 21 of 25}

Psychology of Music

1
2
3
4
5
6
7
8
9
10
11
12
13
14
15
16
17
18
19
20
21
22
23
24
25
26
27
28
29
30
31
32
33
34
35
36
37
38
39
40
41
42
43
44
45
46
47
48
49
50
51
52
53
54
55
56
57
58
59
60

Table 2: Descriptive statistics and correlation coefficients of the variables of the structural model of self-determined motivation

\begin{tabular}{|lcccccccc}
\hline & M & SD & Skewness & Kurtosis & 1 & 2 & 3 & 4 \\
\hline Psychological Needs Satisfaction & 0 & 1.64 & -0.45 & -0.03 & - & & & \\
Autonomous Motivation & 0 & 3.14 & -0.09 & -0.40 & $.53^{*}$ & - & & \\
Practice Frequency & 5.69 & 3.91 & 1.88 & 4.86 & .11 & $.20^{*}$ & - & \\
Quality Practice Frequency & 3.92 & 2.71 & 1.63 & 3.40 & $.16^{*}$ & $.30^{*}$ & $.82^{*}$ & - \\
Preference for Challenge & 5.08 & 1.32 & -0.78 & 0.90 & $.14^{*}$ & $.27^{*}$ & .06 & .08 \\
\hline
\end{tabular}

Note: $N=392 ; * p<.01$ 
Table 3: Pearson correlation coefficients between needs satisfaction, autonomous motivation, practice and affect

\begin{tabular}{|llllll}
\hline Variables & $\begin{array}{l}\text { Psychological } \\
\text { Needs } \\
\text { Satisfaction }\end{array}$ & $\begin{array}{l}\text { Autonomous } \\
\text { Motivation }\end{array}$ & $\begin{array}{l}\text { Practice } \\
\text { Frequency }\end{array}$ & $\begin{array}{l}\text { Quality } \\
\text { Practice } \\
\text { Frequency }\end{array}$ & $\begin{array}{l}\text { Preference } \\
\text { for } \\
\text { Challenge }\end{array}$ \\
\hline Happy & $.38^{*}$ & $.28^{*}$ & .06 & .09 & .08 \\
Relaxed & $.18^{*}$ & -.10 & -.02 & -.03 & -.03 \\
Excited & $.41^{*}$ & $.29^{*}$ & .07 & .09 & .08 \\
Proud & $.24^{*}$ & $-.19^{*}$ & -.04 & -.06 & -.05 \\
Unhappy & -.06 & $-.14^{*}$ & -.03 & -.04 & -.04 \\
Nervous & $-.15^{*}$ & -.02 & -.01 & -.01 & -.01 \\
Guilty & .05 & -.11 & -.03 & -.04 & -.03 \\
Angry & -.03 & -.10 & -.02 & -.03 & -.03 \\
\hline
\end{tabular}

Note: $N=392 ; * p<.01$. 


\section{Page 23 of 25}

Psychology of Music

1

2

3

4

5

6

7

8

9

10

11

12

13

14

15

16

17

18

19

20

21

22

23

24

25

26

27

28

29

30

31

32

33

34

35

36

37

38

39

40

41

42

43

44

45

46

47

48

49

50

51

52

53

54

55

56

57

58

59

60

Figure 1: Structural equation model of psychological needs satisfaction and autonomous motivation predicting practice.

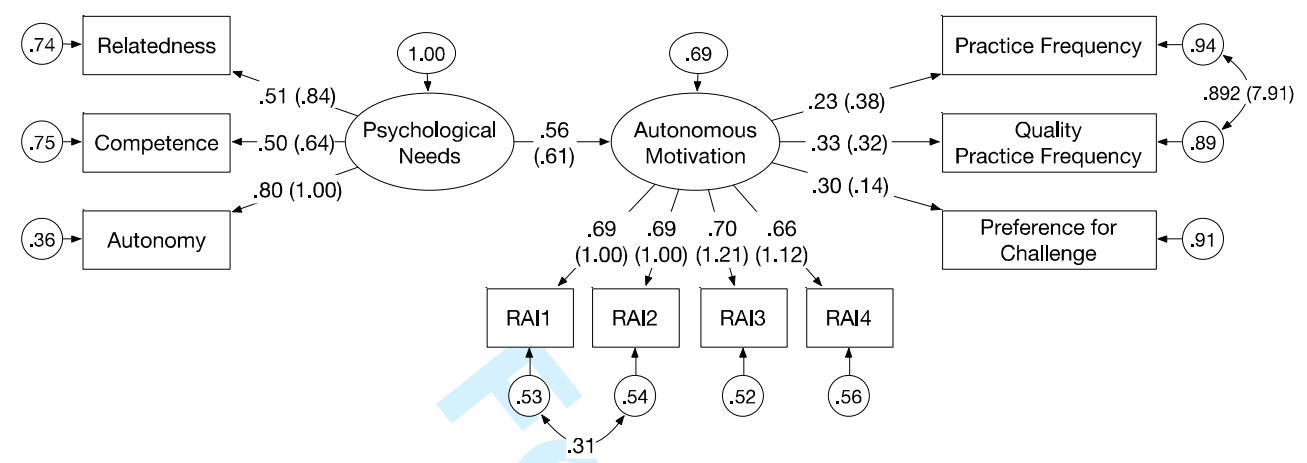

Note. $N=392$; Unstandardized coefficients are in parentheses. All factor loadings and paths are significant at $p<.001$. RAI $=$ Relative Autonomy Index. 


\section{Appendix 1: Items used in BMPN-Music and SRQ-Music scales}

BMPN-Music scale (adapted from Sheldon and Hilpert, 1989)

Relatedness

I feel a sense of contact with others

I feel close and connected with other people who are important to me

I feel a strong sense of intimacy with others

I am somewhat lonely*

I feel unappreciated by one or more important people*

I have disagreements or conflicts with people I usually get along with*

Competence

I struggle doing things I should be good at

I successfully learn difficult music

I take on and master hard challenges

I do stupid things that make me feel incompetent*

I experience failure and am unable to do well*

I do well even at the hard things*

Autonomy

I am able to express my "true self"

I feel free to do things my own way

I am doing what interests me

I have a lot of pressures I could do without*

My teacher or parents tell me what I have to do*

I have to do things against my will*
SRQM-Music (adapted from Ryan and Connell, 1989).

Intrinsic

Because I love playing my instrument

Because I enjoy music lessons

Because I enjoy playing music

Identified

Because I want to be a good musician Because it is important to me to play music

So I can improve my skills as a musician

Introjected

So I can show off my abilities

Because people will think I am a good musician

So I can feel proud of my abilities

Extrinsic

Because I will get in trouble if I don't

Because I am supposed to

I am not allowed to just select easy music to play 


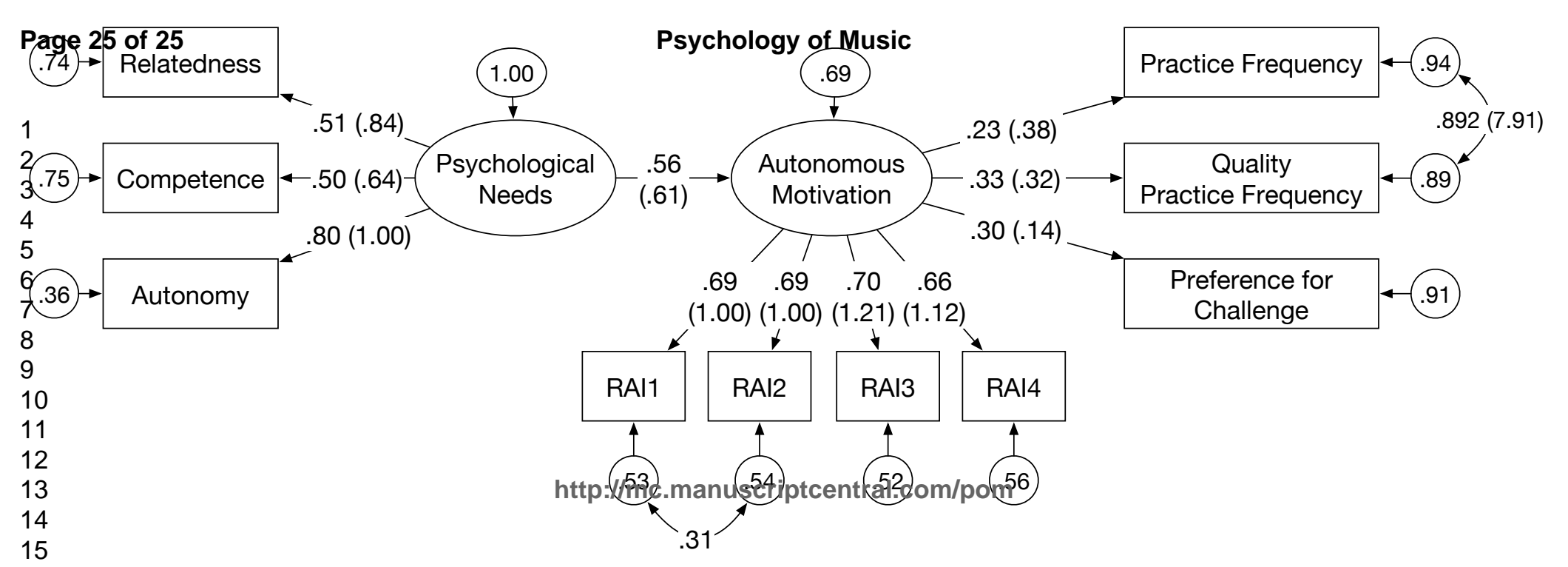

